\title{
Mitigating Coordination Costs in Global Software Development Using Scrum
}

\author{
M. Rizwan Jameel Qureshi, Noha Alsulami \\ Faculty of Computing and Information Technology, King Abdulaziz University, Jeddah, Saudi Arabia \\ Email: anriz@hotmail.com, nalselami09@yahoo.com
}

\begin{abstract}
Global Software Development (GSD) is the most recent and major trend in software engineering domain. It provides many benefits but also faces various challenges in control, communication and coordination due to socio-cultural, geographical and temporal distance. Scrum is increasingly being applied in GSD as it supports teamwork between developers and customers. Scrum method offers a distinctive feature to mitigate the effects of socio-cultural and geographical but not temporal distance on coordination in GSD projects. This paper explains how Scrum helps to mitigate the effects of temporal distance which includes increased coordination costs in GSD projects. A web application called (Distributed Scrum Web Application) provides various advantages for Scrum teams. The main advantage of this application is to facilitate communication among distributed team members.
\end{abstract}

Index Terms-Global software development, scrum, coordination costs, distributed applications, sprint.

\section{INTRODUCTION}

Global Software Development (GSD) is the most recent domain in software engineering [1]. GSD is a software development that is distributed across two or more sites. The sites may be separated by national or continental borders [2]. The various advantages provided by GSD for organizations that develop software are reduction in marketing time, improvement in quality, reducing cost and increasing productivity. However, GSD faces various challenges in control, communication and coordination according to socio-cultural, geographical and temporal distance [1]. The classification of these challenges is mentioned in [2]. Scrum is increasingly being applied in GSD as it provides many advantages like improved communication, trust and quality of product. It also helps to mitigate some challenges [1]. Scrum is a type of agile methodology that is an iterative approach and a time boxed method. It consists of "Sprint" that is an iteration which focuses on planning [1][3]. Many practices of Scrum are used in GSD. Some of these practices are: Sprint, Backlog, Sprint Planning meeting, Daily Scrum meeting and Sprint Review meeting (or Demo) [2].

Sprint is a fixed duration that takes from one to four weeks. Product Backlog contains the list of prioritized tasks that are requested by the user as user stories. At the beginning of each sprint, the set of tasks in product backlog are specified and put on Sprint Backlog after the size of these tasks is estimated during Sprint Planning meeting. Each team member in a team answers three questions which are: (1) what did you do yesterday? (2) what are you doing today? (3) what are the problems you faced when you wanted to achieve your goals? This situation happens in Daily Scrum meetings that take fifteen minutes. Sprint Review meeting is held at the end of each sprint to discuss the accomplished tasks during the Sprint [2][4][5].

This study focuses on the distinctive feature of Scrum that can be used to mitigate the coordination costs in GSD projects due to temporal distance. It also facilitates communication among distributed team members by developing (Distributed Scrum Web Application).

The paper is structured as follows.

Section II presents related work on Scrum practices in GSD projects. Section III describes the problem and proposed solution. Validation of the proposed solution is covered in section IV.

\section{RELATED WORK}

There are many articles present on how Scrum methodology is implemented in GSD environment. The experience of a global company that implemented Scrum in its two projects is mentioned in [3]. It maintained its centers in Americas and Asia. Both projects experienced challenges when Scrum was implemented. One of the challenges was in communication as the teams did not attend remote Scrum meetings and that affected collaboration between them. A bigger challenge was in changing the culture of the company from waterfall to Scrum because there was some resistance by people within the company.

The biggest challenge for implementing Scrum in GSD environment is lack of synchronous communication as reported in [6]. This paper also defined the challenging factors of using Scrum practices in GSD projects and strategies to reduce these factors. While the authors of [1] suggest a framework of research which shows how practices of Scrum can mitigate challenges in GSD. It also defines three categories of challenges in GSD that are control, communication and coordination according to socio-cultural, geographical and temporal distance. However, this framework needs to validate empirically because it is a theoretical proposition. 
An empirical study to implement Scrum practices in GSD projects is reported in [2]. This study was conducted to show the distinctive benefits of applying Scrum method in GSD projects over the traditional methods to mitigate GSD coordination challenges. The result was that Scrum method offered a distinctive feature to mitigate the effects of socio-cultural and geographical, but not temporal distance on coordination in GSD projects. There is a new method for GSD like scRumUP is mentioned in [7]. It integrated the advantages of Rational Unified Process (RUP) that is used for developing software and Scrum that is performed for managing a project.

There are various papers that present case studies about how Scrum is used in GSD context. Some of these studies faced challenges of using Scrum in GSD projects. In [8], there is a case study for a company that implemented and scaled Scrum in its distributed project. There were challenges in implementing and scaling Scrum in this project like communication and collaboration were not working properly between team and area product owner. In spite of the existing challenges, Scrum was implemented successfully and it increased the number of customers. While [9] shows a case study for the 2011 version of the GSD project that is run annually. It used Scrum for developing mobile application and also implemented the IBM Rational Team Concert tool. Scrum helped the developers for finding better ways to implement user requirements. There were difficulties faced by developers when using
Scrum. The source of these difficulties did not come from Scrum, but from the tools implemented in the project and the-distribution of teams across three countries.

Another team faced some challenges at the beginning of teaching course about GSD in collaboration between Victoria University in Canada and Aalto University in Finland. These challenges were cultural differences, timezone differences, technical difficulties and the differences in semesters and courses between two universities as reported in [4]. In [5], there is a case study of a team that developed a Target First Grade project that is a mobile application for children learning mathematics, reading geography and writing. This project took nine weeks to develop. It implemented Scrum and used IBM Rational Team Concert environment as tooling.

There were some problems when Scrum was applied in this project such as: the developers did not work as one team but as three smaller teams. The experience of applying Scrum-of-Scrum meeting (SoS) is mentioned in [10]. It was used for inter-team coordination in two large distributed projects from two companies. SoS did not work effectively in the first project, while a new meeting called Feature SoS was added to the second project and it was very useful. The second project also implemented Grande SoS that is wide SoS meeting, but it caused problems for the teams. So, there were challenges with coordination in both projects when SoS meetings were applied. The limitations of each paper are illustrated in Table 1.

Table 1. Comparison of Related Work

\begin{tabular}{|c|c|}
\hline Paper Title & Limitation \\
\hline $\begin{array}{c}\text { Usage of SCRUM Practices within a } \\
\text { Global Company [3] }\end{array}$ & Both the distributed projects faced communication challenges while using Scrum. \\
\hline $\begin{array}{l}\text { Using Scrum in Global Software } \\
\text { Development: [6] }\end{array}$ & $\begin{array}{l}\text { Papers that are used in this study do not have detailed information about the challenges and } \\
\text { strategies that deal with challenges of GDS projects that implement Scrum practices. }\end{array}$ \\
\hline $\begin{array}{l}\text { Scrum Practices in Global Software } \\
\text { Development [1] }\end{array}$ & The framework needed to validate empirically because it is a theoretical proposition. \\
\hline $\begin{array}{c}\text { Scrum Practice Mitigation of Global } \\
\text { Software Development Coordination } \\
\text { Challenges: A Distinctive Advantage? } \\
{[2]}\end{array}$ & $\begin{array}{l}\text { This study focused only on four out of twelve GSD challenges and also on practices of Scrum } \\
\text { instead of focusing on the mechanisms and tools that help in mitigating challenges. It shows } \\
\text { that Scrum method offers a distinctive feature to mitigate the effects of socio-cultural and } \\
\text { geographical, but not temporal distance on coordination in GSD projects. }\end{array}$ \\
\hline $\begin{array}{c}\text { Scrum-based Methodology for } \\
\text { Distributed Software Development } \\
{[7] .}\end{array}$ & $\begin{array}{l}\text { The result of applying scRumUP methodology is not mentioned because the paper was } \\
\text { written at the same time the company implemented the first project that used scRumUP. }\end{array}$ \\
\hline $\begin{array}{l}\text { Scaling Scrum in a Large Distributed } \\
\text { Project [8] }\end{array}$ & $\begin{array}{l}\text { There were challenges in implementing and scaling Scrum in this paper like communication } \\
\text { and collaboration were not working properly between team and area product owner. This } \\
\text { study also focused on one project and the interviews were in two out of four sites. Most of the } \\
\text { interviews were in the main site for restrictions in time and travelling. }\end{array}$ \\
\hline $\begin{array}{l}\text { On the Difficulties for Students to } \\
\text { Adhere to Scrum on Global Software } \\
\text { Development Projects: Preliminary } \\
\text { Results [9] }\end{array}$ & $\begin{array}{l}\text { There were difficulties faced by developers when using Scrum but they learned many } \\
\text { methods to develop software. The source of these difficulties did not come from Scrum but } \\
\text { from the tools implemented in the project and the distribution of teams across three countries. }\end{array}$ \\
\hline $\begin{array}{c}\text { Teaching a Globally Distributed } \\
\text { Project Course Using Scrum Practices } \\
\text { [4] }\end{array}$ & $\begin{array}{l}\text { The team faced some challenges at the beginning of the project. These challenges were } \\
\text { cultural differences, time-zone differences, technical difficulties and the differences in } \\
\text { semesters and courses between two universities. }\end{array}$ \\
\hline $\begin{array}{l}\text { Transitioning to Distributed } \\
\text { Development in Students' Global } \\
\text { Software Development Projects [5] }\end{array}$ & $\begin{array}{l}\text { There were some problems when Agile and Scrum were applied in this project such as: the } \\
\text { developers did not work as one team but as three smaller teams. }\end{array}$ \\
\hline $\begin{array}{l}\text { Inter-team coordination in large-scale } \\
\text { globally distributed scrum }[10]\end{array}$ & $\begin{array}{l}\text { The results of this paper are limited as it depends on two projects only and it selected } \\
\text { interview method for collecting data. There were challenges with coordination in both } \\
\text { projects when applied SoS meetings. }\end{array}$ \\
\hline
\end{tabular}




\section{PROBLEM AND THE PROPOSED SOLUTION}

Although the literature indicates that the Scrum method is not offering a distinctive feature to mitigate the effect of temporal distance challenge that includes "increased coordination costs" in GSD projects. This research proposed solution by considering some factors such as reducing the time of communication between distributed Scrum teams' as much as possible and using technologies. So, the Scrum method can offer a minor distinctive feature to mitigate the effect of temporal distance challenge.

Based on the difference in time zones between sites in GSD, the time of communication between distributed Scrum teams can be reduced by dividing the Scrum meetings into local meeting and global meeting.

Local meeting should be held in each site, while global meeting should be held between sites. This division will minimize hours of Scrum meetings and the number of persons in each meeting. In addition, this paper suggests developing a web application to improve communication between distributed sites.

Fig. 1 presents the proposed structure for implementing Scrum in GSD environment that is derived from multiple case studies in [11] with new additions. It is designed for a company with distributed sites (main site onshore and distributed site offshore). Main site (site A) has three persons (product owner/project manager, test engineer and architect as minimum) and server that is connected to database. In each offshore site, there is one Scrum master and Scrum team. The onshore team is responsible for maintaining the product backlog, creating the specification for the sprint backlog at offshore sites and verifying completed software before delivery to customers. The offshore team members are involved as single Scrum team in the development. For example, if project members work with each other in large time difference zones between these sites, there will be increased coordination costs between sites. This problem can be solved by applying general mechanisms as presented in [2]; however, Scrum does not offer a distinctive advantage to mitigate coordination costs.

The proposed structure presents a distinctive feature of Scrum to reduce the coordination cost by applying the proposed solution. The length of Sprint is two weeks in this structure. After applying this structure, the duration of Scrum meetings is reduced.

At the beginning of Sprint, the Sprint Planning meeting is divided into three meetings: Sprint pre-planning meeting, global sprint planning meeting and local sprint planning meeting. Sprint pre-planning meeting is held online between onshore and offshore sites to provide the details of tasks that are required in the next sprint from onshore site to offshore sites. The product owner/ project manager, Scrum Master in site B and Scrum master in site $\mathrm{C}$ who attend this meeting which takes one and a half hours instead of two hours by synchronizing hours between them and using web application for communication. Then Scrum Masters conduct an online global sprint planning meeting which takes two hours via web application to divide tasks between offshore sites. Finally, each Scrum Master holds face to face local sprint planning meeting which takes an hour with his team to assign tasks to them. So the time of sprint planning at offshore sites is three hours instead of four hours.

Daily Scrum meeting is divided into two parts: local daily scrum meeting and global daily scrum meeting. Each Scrum Master holds face to face a local daily scrum meeting with his team to answer three questions as mentioned before. This meeting usually takes five to seven minutes. Then global daily scrum is held online between two scrum masters in offshore sites for eight minutes via web application. So the time of Daily Scrum meeting at offshore sites is decreased from fifteen minutes to seven or eight minutes.

Sprint review Meeting is divided into three parts: local sprint review, global sprint review and sprint review meetings. First, local sprint review is held face to face in each offshore site between Scrum Master and his team for half an hour. Then global sprint review is held online between two Scrum Masters in offshore sites to discuss the accomplished tasks during the sprint for an hour via web application. Finally, sprint review meeting is held online between two Scrum Masters and onshore site for an hour and a half via web application. So the total hours of those meetings are three hours instead of four hours.

A new meeting is added that is called suggestions meeting. It is held online between product owner/project manager, two Scrum masters in offshore sites and customers to discuss the suggestions that are provided by team members every two weeks for one to two hours via web application. 


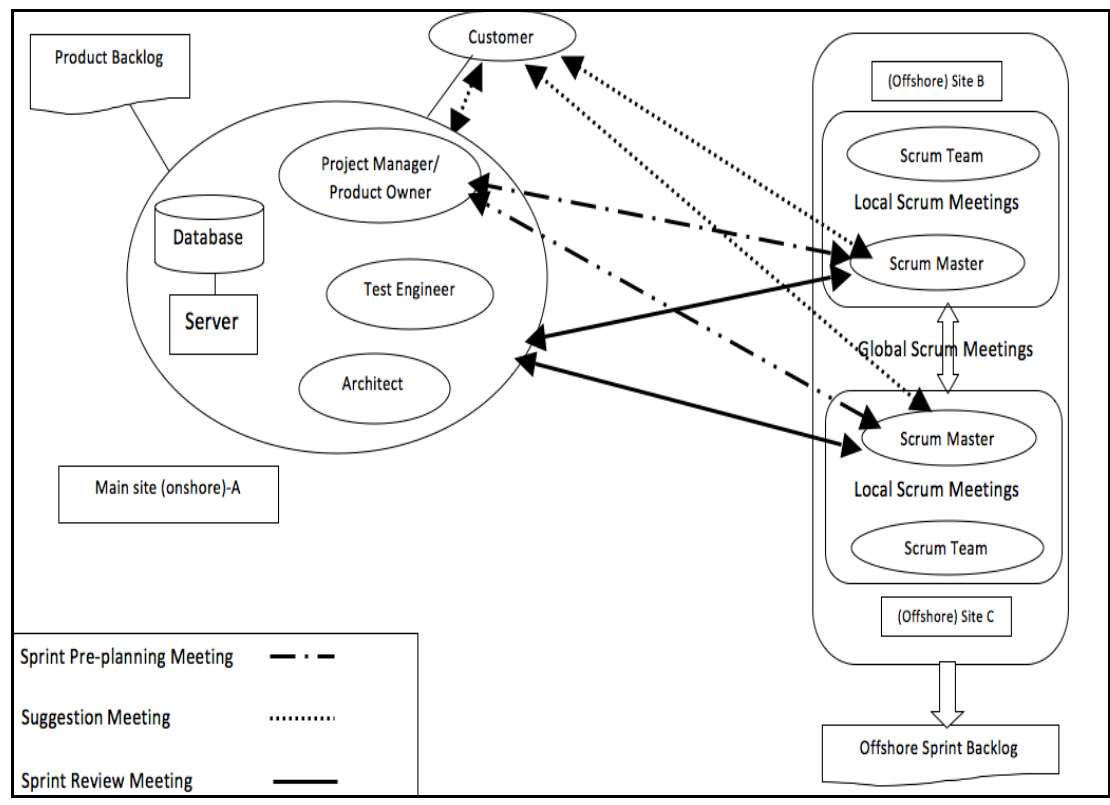

Fig. 1. The Proposed Structure

As a result, the proposed solution saves team member's time by reducing the number of meetings and decreasing the number of hours of these meetings. They can focus on their tasks and work more effectively.

The communication between teams in distributed sites is improved by developing a web application (Distributed Scrum Web Application) that helps teams to facilitate their work. Web application will provide different advantages like:

(1) Security: It is ensured by specifying the privileges for each member by creating user account and assigning privileges to each one.

(2) Availability: The web is available all the time and any member can access it.

(3) Easier maintenance

(4) Easier to develop e.g. by using .Net that facilitates the development by providing components.

(5) Reducing costs on client side by requiring only the web browser that can access the server.

Web application helps teams by providing many services such as:

(1) Organization: each member in a team can access one place (website) to find what he wants to complete the work effectively. So, instead of using traditional tools like Skype or wiki the needed tools for communication or Scrum are built to provide security and reliability. This web application organizes the work between sites and within each site by scheduling all the work and meetings.

(2) Therefore, the web application provides reminder service about various activities.

(3) Online Training: provides workshops that are presented by onshore site for distributed teams instead of visiting the onshore site to train. Moreover, workshops can be recorded and added to the library that contains recordings of either workshops or meetings that occurred. Hence, the time and cost of travelling are saved.

(4) Suggestions: each member can suggest and these suggestions can be discussed in suggestions meeting.

(5) Supporting the team by providing materials that help team members and answering their questions at any time.

(6) Improving communication between different sites either by using video conference, chatting, or other tools that are available in web application.

(7) Tracking: the team leader can track the work of his team. The project manager/ product owner can track all the work in distributed sites.

Although team members work in different time zones in the world, (Distributed Scrum Web Application) will leverage and document the communication among team members. In fact, it will enhance the quality of the project and team members' understanding of the project when they deal with tasks and allow them to offer suggestions that improve the outcome of the project.

\section{VALIDATION}

Survey is used as a research method to validate the proposed solution by distributing an electronic questionnaire to developers in software engineering domain through email. This survey used likert scale in answering questions. Likert scale ranges from 1 to 5 .

- Very low effect indicating 1

- Low effect indicating 2

- Nominal/Average effect indicating 3

- High effect indicating 4

- Very high effect indicating 5 
The responses of this survey were collected from thirty respondents. The statistical analysis of these responses will be presented in the following subsections.

\section{A. Cumulative Analysis of the First Goal}

The first goal consists of five questions and focuses on the importance of Scrum meetings.

Table 2 shows the cumulative analysis of goal 1. Fig. 2 clearly shows that $49.2 \%$ of respondents agree and $11.4 \%$ of respondents strongly agree to the fact that division of Scrum meetings is very important, although $2.8 \%$ disagree and $36.6 \%$ are neutral.

Table 2. Cumulative analysis of goal 1

\begin{tabular}{|c|c|c|c|c|c|}
\hline Q. No. & Very Low & Low & Nominal & High & Very High \\
\hline 1 & 0.00 & 0.00 & 37.00 & 53.00 & 10.00 \\
\hline 2 & 0.00 & 0.00 & 33.00 & 50.00 & 17.00 \\
\hline 3 & 0.00 & 0.00 & 20.00 & 70.00 & 10.00 \\
\hline 4 & 0.00 & 4.00 & 50.00 & 33.00 & 13.00 \\
\hline 5 & 0.00 & 10.00 & 43.00 & 40.00 & 7.00 \\
\hline Total & 0.00 & 14.00 & 183.00 & 246.00 & 57.00 \\
\hline Avg. & $0.00 \%$ & $2.8 \%$ & $36.6 \%$ & $49.2 \%$ & $11.4 \%$ \\
\hline
\end{tabular}

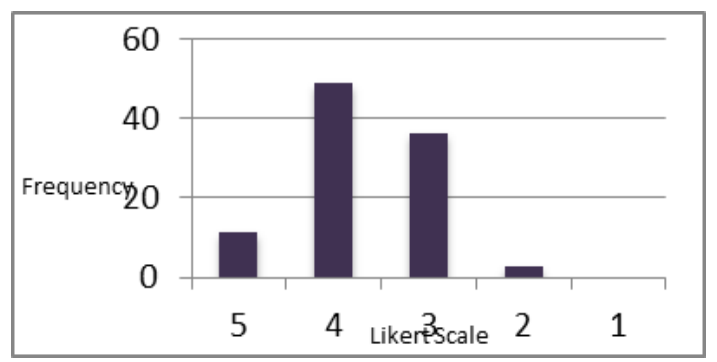

Fig. 2. The cumulative results for goal 1

\section{B. Cumulative Analysis of the Second Goal}

The second goal consists of 8 questions, and focuses on the importance of developing web applications.

Table 3 shows the cumulative analysis of goal 2. Fig. 3 clearly shows that $53.75 \%$ respondents agree and $17.75 \%$ strongly agree to the fact that there is importance of developing web application, even though $28.5 \%$ remained neutral.

Table 3. Cumulative analysis of goal 2

\begin{tabular}{|l|l|l|l|l|l|}
\hline Q. No & Very Low & Low & Nominal & High & Very high \\
\hline 6 & 0 & 0 & 20.00 & 60.00 & 20.00 \\
\hline 7 & 0 & 0 & 23.00 & 57.00 & 20.00 \\
\hline 8 & 0 & 0 & 37.00 & 53.00 & 10.00 \\
\hline 9 & 0 & 0 & 27.00 & 50.00 & 23.00 \\
\hline 10 & 0 & 0 & 17.00 & 73.00 & 10.00 \\
\hline 11 & 0 & 0 & 30.00 & 40.00 & 30.00 \\
\hline 12 & 0 & 0 & 57.00 & 27.00 & 16.00 \\
\hline 13 & 0 & 0 & 17.00 & 70.00 & 13.00 \\
\hline Total & 0 & 0 & 22.8 & 43.0 & 14.2 \\
\hline Avg. & $0 \%$ & $0 \%$ & $28.5 \%$ & $53.7 \%$ & $17.75 \%$ \\
\hline
\end{tabular}

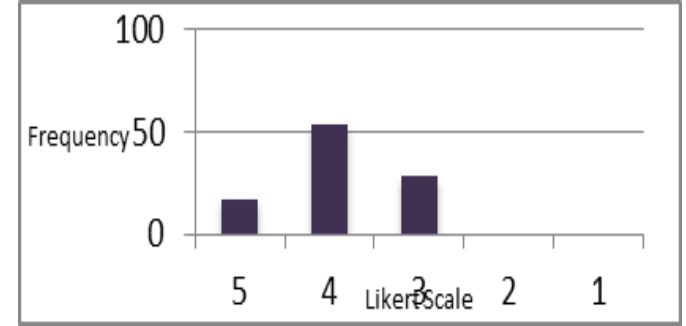

Fig. 3. The cumulative results for goal 2

\section{Cumulative Analysis of the Third Goal}

The third goal is consists of four questions and shows how the proposed solution will save the time of the project.

Table 4 shows the cumulative analysis of goal 3. Fig. 4 clearly shows that $52 \%$ of respondents agree and $20.75 \%$ of respondents strongly agree to the fact that the proposed solution will save the time of the project, although $27.25 \%$ remained neutral.

Table 4. Cumulative analysis of goal 3

\begin{tabular}{|c|c|c|c|c|c|}
\hline Q. No. & Very Low & Low & Nominal & High & Very High \\
\hline 14 & 0.00 & 0.00 & 30.00 & 43.00 & 27.00 \\
\hline 15 & 0.00 & 0.00 & 33.00 & 54.00 & 13.00 \\
\hline 16 & 0.00 & 0.00 & 23.00 & 54.00 & 23.00 \\
\hline 17 & 0.00 & 0.00 & 23.00 & 57.00 & 20.00 \\
\hline Total & 0.00 & 0.00 & 109 & 208 & 83 \\
\hline Avg. & $0.00 \%$ & $0.00 \%$ & $27.25 \%$ & $52 \%$ & $20.75 \%$ \\
\hline
\end{tabular}

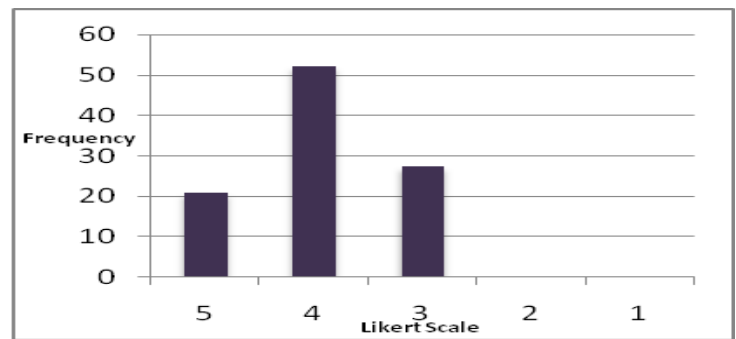

Fig 4. The cumulative results for goal 3

\section{Cumulative Analysis of the Fourth Goal}

The fourth goal consists of three questions and shows how the proposed solution will save the cost of the project.

Table 5 shows the cumulative analysis of goal 4. Fig. 5 clearly shows that $59.33 \%$ agreed and $21 \%$ strongly agreed to the fact that the proposed solution will save the cost of the project, although $19.67 \%$ of respondents remained neutral.

Table 5. Cumulative analysis of goal 4

\begin{tabular}{|c|c|c|c|c|c|}
\hline Q. No. & Very Low & Low & Nominal & High & Very High \\
\hline 18 & 0.00 & 0.00 & 13.00 & 57.00 & 30.00 \\
\hline 19 & 0.00 & 0.00 & 23.00 & 57.00 & 20.00 \\
\hline 20 & 0.00 & 0.00 & 23.00 & 64.00 & 13.00 \\
\hline Total & 0.00 & 0.00 & 59 & 178 & 63 \\
\hline Avg. & $0.00 \%$ & $0.00 \%$ & $19.67 \%$ & $59.33 \%$ & $21 \%$ \\
\hline
\end{tabular}




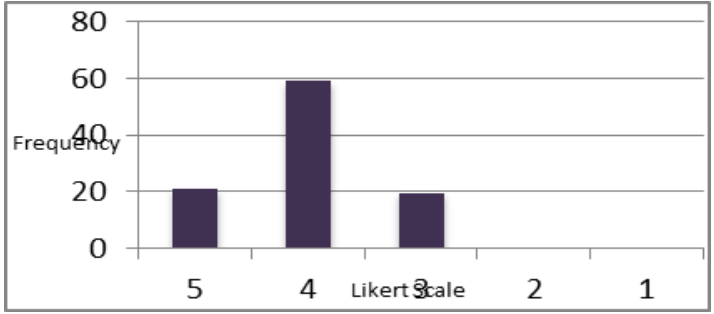

Fig. 5. The cumulative results for goal 4

\section{CONCLUSION}

This study focuses on how Scrum can be used to offer a distinctive feature in mitigating the effect of increased coordination costs in GSD projects by offering a solution that is dividing the Scrum meetings into local meeting and global meeting to reduce the time of communication between distributed Scrum teams. In addition, develop (Distributed Scrum Web Application) to facilitate the communication among distributed team members and provide various services. So, the proposed solution offers a distinctive feature to mitigate the effects of "increased coordination costs" challenge on coordination in GSD projects.

\section{REFERENCES}

[1] Hossain, E., Bannerman, P. and Jeffery, D. Scrum Practices in Global Development: A Research Framework. In: Proceedings of the $12^{\text {th }}$ International Conference on Product Focused Software Process Improvement (PROFES), 2011, pp. 88-102.

[2] Bannerman, P. L., Hossain, E. and Jeffery, R. Scrum Practice Mitigation of Global Software Development Coordination Challenges: A Distinctive Advantage?" In: Proceedings of the 45th Hawaii International Conference on System Sciences, 2012, pp. 5309-5318.

[3] Cristal, M., Wildt, D. and Prikladnicki, R. Usage of SCRUM Practices within a Global Company. In: Proceedings of the IEEE International Conference on Global Software Engineering, 2008, pp. 222-226.

[4] Damian, D., Lassenius, C., Paasivaara, M., Borici, A. and Schr"oter, A. Teaching a Globally Distributed Project Course Using Scrum Practices. In: Proceedings of the CTGDSD Conference, 2012, pp. 30-34.

[5] Scharff, C., Gotel, O., and Kulkarni, V. Transitioning to Distributed Development in Students' Global Software
Development Projects: The Role of Agile Methodologies and End-to-End Tooling. In: Proceedings of the 5th International Conference on Software Engineering Advances, 2010, pp. 388-394.

[6] Hossain, E., Babar, M.A., and Paik, H. Using Scrum in Global Software Development: A Systematic Literature Review. In: Proceedings of the 4th IEEE International Conference on Global Software Engineering, 2009, pp. 175-184.

[7] Nuevo, E.D., Piattini, M., and Pino, F.J. Scrum-based Methodology for Distributed Software Development. In: Proceedings of the 6th IEEE International Conference on Global Software Engineering, 2011, pp. 66-74.

[8] Paasivaaraand, M., and Lassenius, C. Scaling Scrum in a Large Distributed Project. In: Proceedings of the International Symposium on Empirical Software Engineering and Measurement, 2011, pp. 363-367.

[9] Scharff, C., Heng, S. and Kulkarni, V. On the Difficulties for Students to Adhere to Scrum on Global Software Development Projects: Preliminary Results. In: Proceedings of the CTGDSD Conference, 2012, pp. 25-29.

[10] Paasivaara, M., Lassenius, C. and Heikkil, V. Inter-team coordination in large-scale globally distributed scrum: Do Scrum-of-Scrums really work? In: Proceedings of the ESEM Conference, 2012, pp. 235-238.

[11] Hossain, M. Scrum Practice Mitigation of Coordination Challenges in Global Software Development Projects: An Empirical Study. The University of New South Wales in Sydney, Australia, 2011, pp. 1-17.

\section{Authors' Profiles}

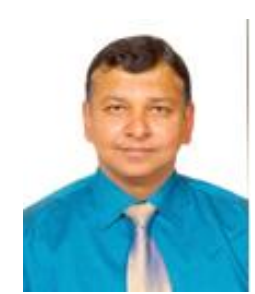

M. Rizwan Jameel Qureshi received his $\mathrm{Ph} . \mathrm{D}$. Computer Science degree from National College of Business Administration \& Economics, Pakistan 2009. This author is best researcher awardees from Department of Information Technology, King Abdulaziz University, Jeddah, Saudi Arabia in 2013 and Department of Computer Science, COMSATS Institute of Information Technology, Lahore, Pakistan in 2008.

Noha Ateeq Alsulami is a master student in IT Department at King Abdulaziz University, interested in agile development.

How to cite this paper: M. Rizwan Jameel Qureshi, Noha Alsulami,"Mitigating Coordination Costs in Global Software Development Using Scrum", IJIEEB, vol.6, no.3, pp.16-21, 2014. DOI: 10.5815/ijieeb.2014.03.03 